\title{
Strongyloides stercoralis disseminated infection and schistosomiasis in an AIDS patient
}

\author{
Rodrigo Martins Brandãoa, Renata Paula Martins Brandão, \\ Amanda Cristina Maria Aparecida Gonçalves ${ }^{c}$, Lorena Silva Labordaa, \\ Patricia Picciarelli de Lima ${ }^{d}$, Fernando Peixoto Ferraz de Campos ${ }^{a}$
}

Brandão RM, Brandão RPM, Gonçalves ACMA, Laborda LS, Lima PP, Campos FPF. Strongyloides stercoralis disseminated infection and schistosomiasis in an AIDS patient. Autopsy Case Rep [Internet]. 2012;2(4):35-44. http:// dx.doi.org/10.4322/acr.2012.035

\section{ABSTRACT}

Strongyloides stercoralis hyperinfection syndrome is classically associated with impaired host response and implies in an overburden of larvae in its usual cycle. It has been recognized as a severe and potentially fatal condition in immunocompromised individuals, especially those using oral corticosteroids. Infection with Schistosoma mansoni not only increases the susceptibility to HIV infection, but also promotes progression to disease. The association of the most severe forms of strongyloidiasis and AIDS is scarcely described, even more when S. mansoni is also associated. The authors describe a case of a 34-year-old previously healthy male, admitted to the emergency department with a history of hematemesis associated with dyspnea, hemoptysis, and fever. He referred homosexual relations for 6 years. Physical examination showed an ill-looking patient, and was remarkable for tachycardia, tachypnea, diaphoresis, and pulse oximetry of $70 \%$ in room air. Lungs examination revealed the presence of rales in the left base. Chest radiography showed a diffuse and bilateral reticulo-nodular pattern. HIV serology was positive. Empirical antimicrobial therapy and corticosteroids were initiated. On the third day of hospitalization, petechiae appeared over the periumbilical area, but no further investigation was undertaken because the patient died soon after. The autopsy findings were compatible with $S$. stercoralis disseminated infection, a hepatic intestinal chronic form of schistosomiasis, and septic shock as the primary cause of death. The authors call attention to this infrequent association.

Keywords: Acquired immunodeficiency syndrome; Strongyloides stercoralis; Schistosoma mansoni; Respiratory insufficiency; Autopsy.

\footnotetext{
a Department of Internal Medicine - Hospital Universitário - Universidade de São Paulo, São Paulo/SP - Brazil.

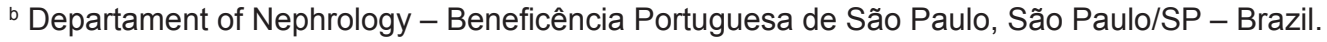

c Nursing Departament - Hospital Israelita Albert Einstein - São Paulo/SP - Brazil.

${ }^{d}$ Anatomic Pathology Service - Hospital Universitário - Universidade de São Paulo, São Paulo/SP - Brazil.
} 


\section{CASE REPORT}

A 34-year-old, previously healthy male patient, born in the northeast of Brazil who had recently moved to the city of São Paulo, was admitted to the emergency department with a history of moderate hematemesis associated with dyspnea, hemoptysis, and a non-measured fever for 4 days. $\mathrm{He}$ denied other gastrointestinal or genitourinary complaints, as well as illicit drug use, and was not taking any medications. He referred homosexual relations with a single partner for 6 years.

Physical examination on admission revealed an ill-looking patient presenting tachycardia (pulse rate $=136$ beats per minute), blood pressure $=100 / 58 \mathrm{mmHg}$, tachypnea (respiratory rate $=34$ respiratory movements per minute) diaphoresis, coma Glasgow scale $=15$, and pulse oximetry of $70 \%$ in room air. Lungs examination revealed the presence of rales in the left base. The examination of the heart, abdomen, and limbs was normal. Endoscopy revealed the presence of hemorrhagic pangastritis without active bleeding, and moderate duodenitis. The bronchoscopy showed sparse mucosal bleeding with some blood clots adhered to the bronchial mucosa, but failed to show any obvious bleeding source.

Chest radiography showed a diffuse and bilateral reticulo-nodular pattern. Two blood culture samples and the microbiological examination of the broncoalveolar lavage was negative for bacterial, fungi, or acid-fast bacilli. The initial laboratory workup is shown in The HIV serology was positive, viral load was $>500,000$ copies ( $\log >5,7$ ) and CD4 count was 58 cells $/ \mathrm{mm}^{3}$.

Because of progressive respiratory insufficiency, the patient was transferred to the Intensive Care Unit where, after attempting to optimize therapy, orotracheal intubation was undertaken, and hemodynamic stabilization required vasoactive drugs. Table 1.

Empirical antimicrobial therapy was initiated with trimethoprim-sulfamethoxazole, ceftriaxone, and clarithromycin plus prednisone. On the third day of hospitalization, petechiae appeared over the periumbilical area. On this day another bronchoscopy was held attempting to collect another search on broncoalveolar lavage and lung biopsy. Neither the biopsy nor the lavage did not help with the diagnosis. A few hours after the procedure, the patient developed a refractory shock, fever (axillary temperature of $41.9^{\circ} \mathrm{C}$ ), cardiac arrest, and death. An autopsy was carried out.

The external examination was unremarkable. External gross examination of the brain was normal, but at microscopy a mild meningeal inflammatory infiltrate in an organization stage was observed (Figure 1A). In a single slide of the brain parenchyma, a unique filamentary structure was detected in the perivascular location (Figure 1B). This finding, despite being single and with degenerative changes, was considered to supposedly be a filariform larva of Strongyloides stercoralis. Exhaustive searches in

Table 1 - Initial laboratory workup

\begin{tabular}{cccccc}
\hline Exam & Result & RV & Exam & Result & RV \\
\hline Hemoglobin & 9.8 & $12.3-15.3 \mathrm{~g} \%$ & Creatinine & 0.6 & $0.4-.3 \mathrm{mg} / \mathrm{dL}$ \\
Hematocrit & 28.5 & $36-45 \%$ & AST & 79 & $10-35 \mathrm{U} / \mathrm{L}$ \\
Leukocytes & 20.4 & $4.4-11.3 \times 10^{3} / \mathrm{mm}^{3}$ & ALT & 84 & $9-43 \mathrm{U} / \mathrm{L}$ \\
Myelocytes & 1 & $0 \%$ & LDH & 405 & $120-246 \mathrm{U} / \mathrm{L}$ \\
Metamyelocytes & 3 & $0 \%$ & Amylase & 106 & $20-104 \mathrm{U} / \mathrm{L}$ \\
Rods & 34 & $1-5 \%$ & Albumin & 3.1 & $3-5 \mathrm{~g} / \mathrm{dL}$ \\
Segmented & 53 & $45-70 \%$ & Lactate & 7.4 & $4.5-19.8 \mathrm{mg} / \mathrm{dL}$ \\
Eosinophils & 0 & $1-4 \%$ & CRP & 140 & $<5 \mathrm{mg} / \mathrm{L}$ \\
Basophils & 0 & $0-2.5 \%$ & & & \\
Lymphocytes & 2 & $18-40 \%$ & & & \\
Monocytes & 7 & $2-9 \%$ & & & \\
Platelets & 283 & $150-450 \times 10^{3} / \mathrm{mm}^{3}$ & & & \\
\hline
\end{tabular}

$\mathrm{AST}$ = aspartate aminotransferase $; \mathrm{ALT}$ = alanine aminotransferase $; \mathrm{CRP}=\mathrm{C}$ reactive protein; $\mathrm{LDH}$ = lactate dehydrogenase; $\mathrm{RV}=$ reference value. 
other areas of the brain could not detect any other similar lesion.

Gross examination of the thoracic cavity disclosed enlarged lungs showing a wine-colored and rubbery consistency. The right lung weighed $1100 \mathrm{~g}$ (reference value $(\mathrm{RV}$ ) range $=360-570 \mathrm{~g}$ ) and the left lung weighed $1240 \mathrm{~g}(\mathrm{RV}$ range $=325-480 \mathrm{~g})$.
Cut surface exhibited a glossy, wine-colored and friable surface compatible with shock.

Microscopic examination revealed extensive intra-alveolar hemorrhage, diffuse alveolar damage, and the presence of a hyaline membrane (Figure 2A), as well as areas of a healing process (Figure 2B).

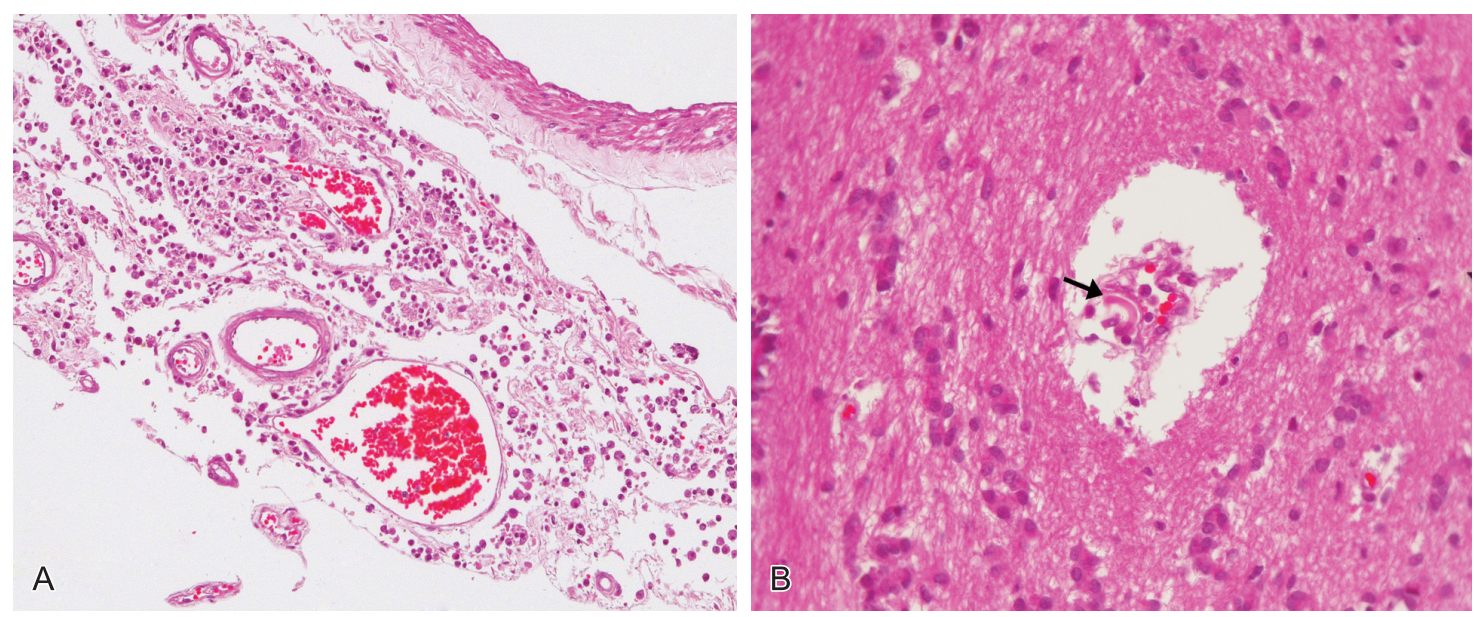

Figure 1 - A - Photomicrography (HE) of the meninges showing mild mixed inflammatory infiltration; B - Photomicrography (HE) of the brain tissue: showing filamentary structure suggestive of filariform larva of Strongyloides stercoralis (arrow).
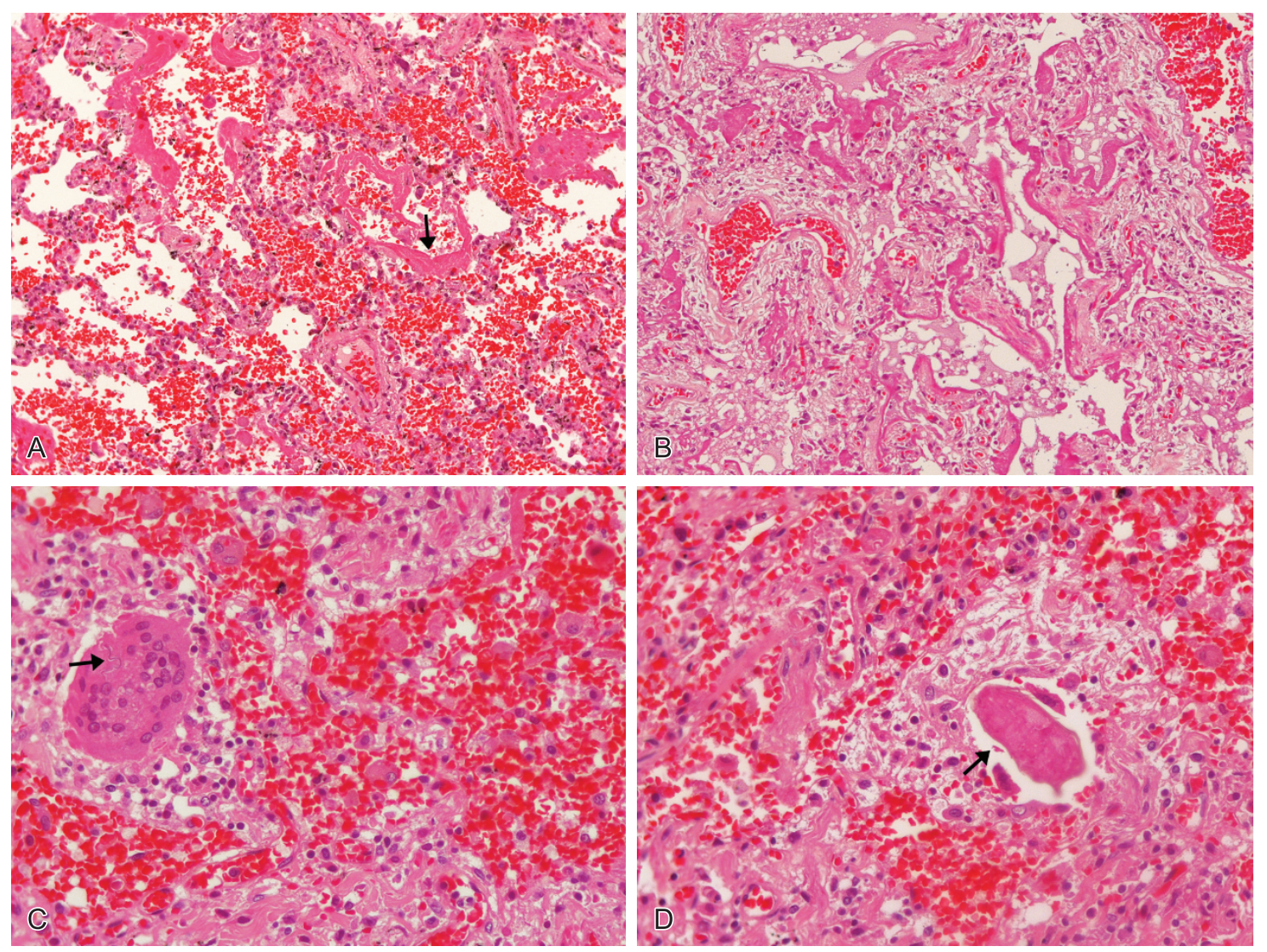

Figure 2 - Photomicrography (HE) of the lung showing: A - Intra-alveolar hemorrhage and diffuse alveolar damage with hyaline membrane formation (arrow); B - Areas of organization; C - Fragments of Strongyloides stercoralis larvae (arrow) partially wrapped in giant cells; D - S. mansoni eggs (arrow), with macrophage with giant cells, and epithelioid cell reaction, sketching granulomas. 
The microscopic examination of the lungs also revealed fragments of structures compatible with the diagnosis of infective larvae of $S$. stercoralis partially surrounded by giant cells (Figure 2C). Additionally, eggs of $S$. mansoni were detected (Figure 2D). Theses eggs were partially wrapped by macrophages, giant cells, and epithelioid cells, sketching out a granuloma. Stains for AFB and fungi were negative.

The liver was enlarged, yellowish, and had a soft consistency (Figure 3A). The cut surface showed multiple parenchymal bleeding points, which were represented, on microscopy, by ischemic areas of the centrilobular zone III and microvesicular steatosis (Figures $3 \mathrm{~B}$ and $3 \mathrm{C}$ ). These findings were concordant with the diagnosis of shock. The microscopic study of the liver showed infective larvae of $S$. stercoralis partially wrapped by giant cells (Figure $3 C$ ), as well as eggs of $S$. mansoni (Figure 3D), also wrapped by macrophage, giant cells, and epithelioid cells forming a granuloma.
Gross examination of the stomach revealed extensive hemorrhagic gastritis (Figure 4A). On microscopy, numerous viable adult $S$. stercoralis females were found in the mucosa (Figures 4B, $4 \mathrm{C}$, and 4D). The duodenum accompanied the hemorrhagic pattern, with areas of mucosal necrosis (Figure $5 A$ ) and countless $S$. stercoralis adult females were detected as well (Figures $5 \mathrm{~B}$, $5 C$, and 5D).

In the large intestine, there was no hemorrhagic or ischemic mucosa, but larvae of $S$. stercoralis (Figure 6A) were also detected in the submucosa, as well as eggs of $S$. mansoni in the mucosa (Figures 6B and 6C).

Microscopic examination of the urinary bladder showed calcified eggs of $S$. mansoni in the mucosa (Figure 7A), and the presence of adult worms of S. mansoni within the venules (Figures 7B and $7 C$ ). Eggs of $S$. mansoni were also found in the seminal vesicle (Figure 7D, arrows). Generalized
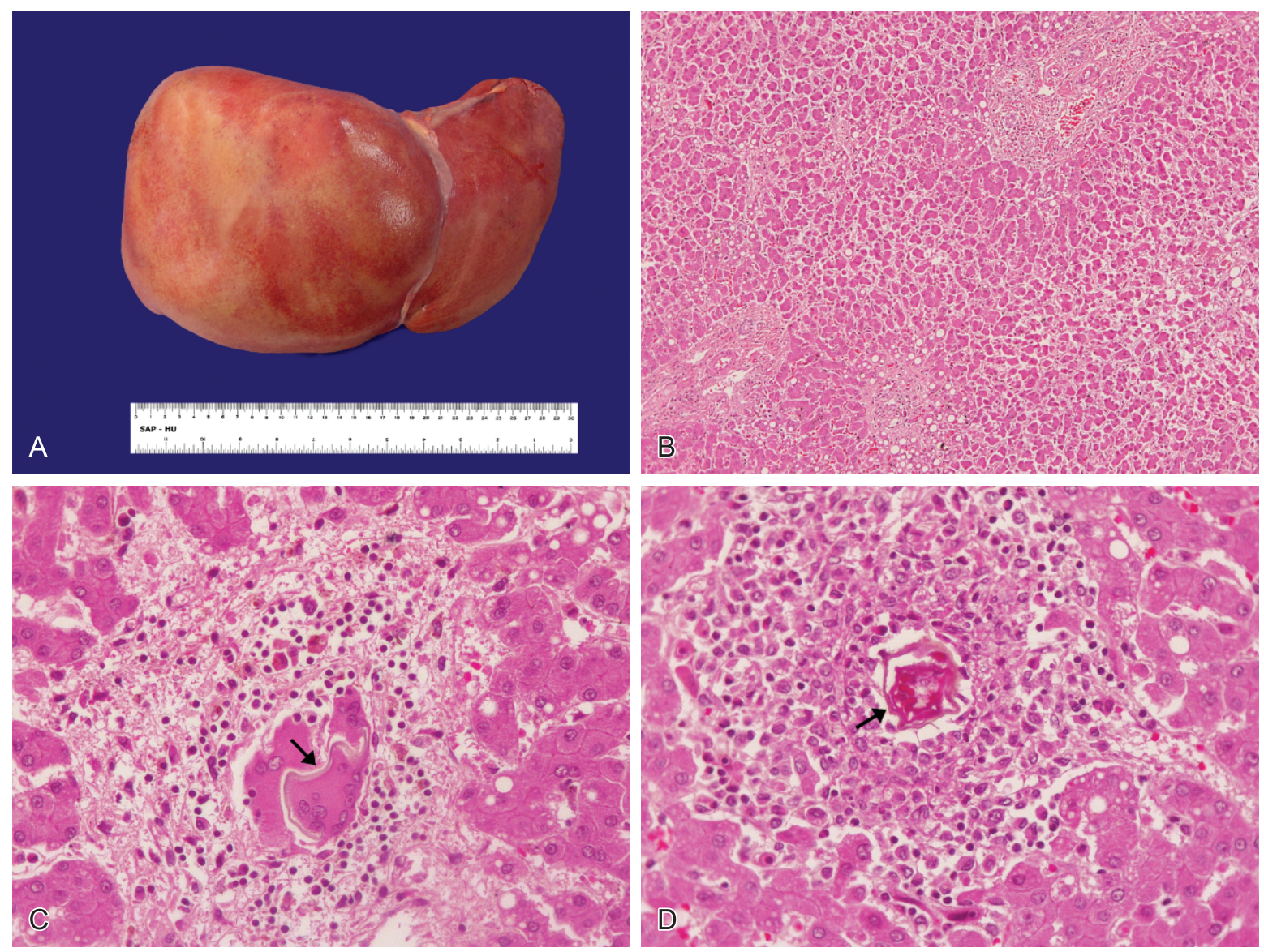

Figure 3 - A - Gross examination of the liver showing an enlarged and yellowish organ; B - Photomicrography (HE) of the liver showing areas of ischemic centrilobular hepatocytes; $\mathbf{C}$ - Photomicrography (HE) of the liver showing fragments of $S$. stercoralis larvae, partially wrapped by giant cells; D - Photomicrography (HE) of the liver showing egg of $S$. mansoni (arrow) eliciting macrophage reaction, giant cells and epithelioid cells reaction, and granuloma formation. 

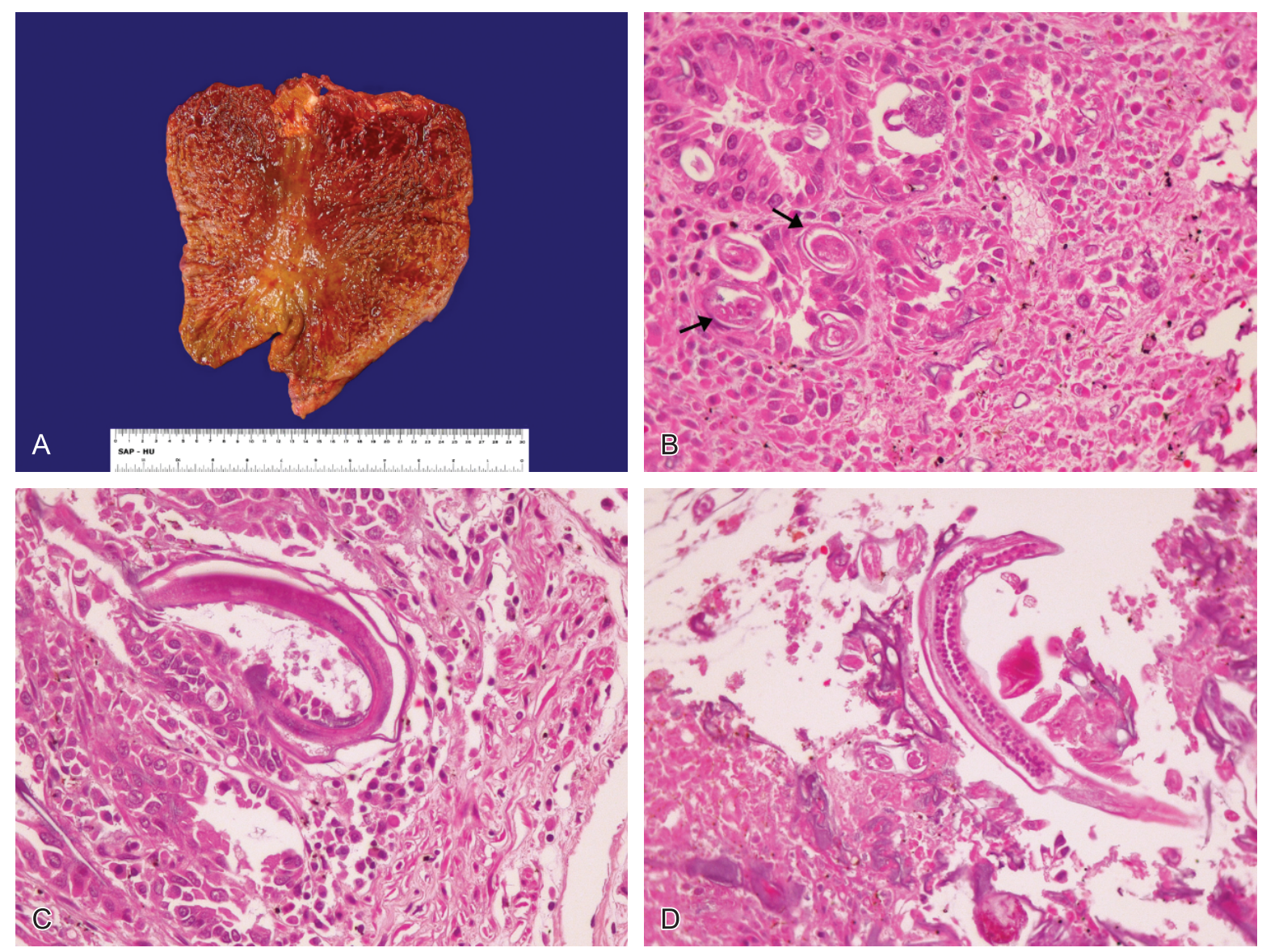

Figure 4 - A - Gross examination of the stomach with extensive hemorrhagic gastritis; B, C, and D - Photomicrography (HE) of the stomach showing many adult females of $S$. stercoralis within the mucosal layer (arrows).

visceral congestion and reactive bone marrow were the remaining findings.

\section{DISCUSSION}

S. stercoralis is an intestinal parasite, endemic in tropical and temperate areas of the world where climatic conditions of humidity and temperature allow their development and survival. ${ }^{1}$

Approximately 100 million people are infected worldwide. ${ }^{1}$ Low social and economic conditions, alcoholism, institutionalized patients, and farm workers are important risk factors for infection by $S$. stercoralis. ${ }^{1,2}$ HIV-1 infection and the use of corticosteroids are also described as risk factors for hyperinfection and development of disseminated forms of the disease. ${ }^{3}$ The prevalence of infection with $S$. stercoralis in AIDS patients in Brazil also seems to be high, varying with location, and ranging from $2.5 \%$ to $21.9 \%{ }^{4}$
Schistosomiasis, in turn, is also a common parasitic disease, considered to be of public health significance in many countries, and affecting around 207 million people in tropical and subtropical areas of the globe. ${ }^{5,6}$ In Brazil, the northeastern states represent the region of higher prevalence of this disease, which is where the patient of this report came from.

The chronic stage of schistosomiasis appears months to years after infection and results from granuloma formation around the schistosome eggs, which are entrapped in many tissues. Depending on the stage of the infection, the granulomas show different characteristics. In the acute phase, they are bulky and exhibit a necrotic-exudative pattern, with large numbers of macrophages, lymphocytes, and eosinophils. ${ }^{7,8} \mathrm{As}$ the disease progresses to the chronic phase, the granulomas lose the exudative necrosis and some of them are found enclosing already calcified eggs. ${ }^{2}$ Along with the lack of hepatic portal fibrosis, it is likely that the patient of this case report presented with a previous subclinical chronic hepatointestinal form of schistosomiasis. ${ }^{3}$ 

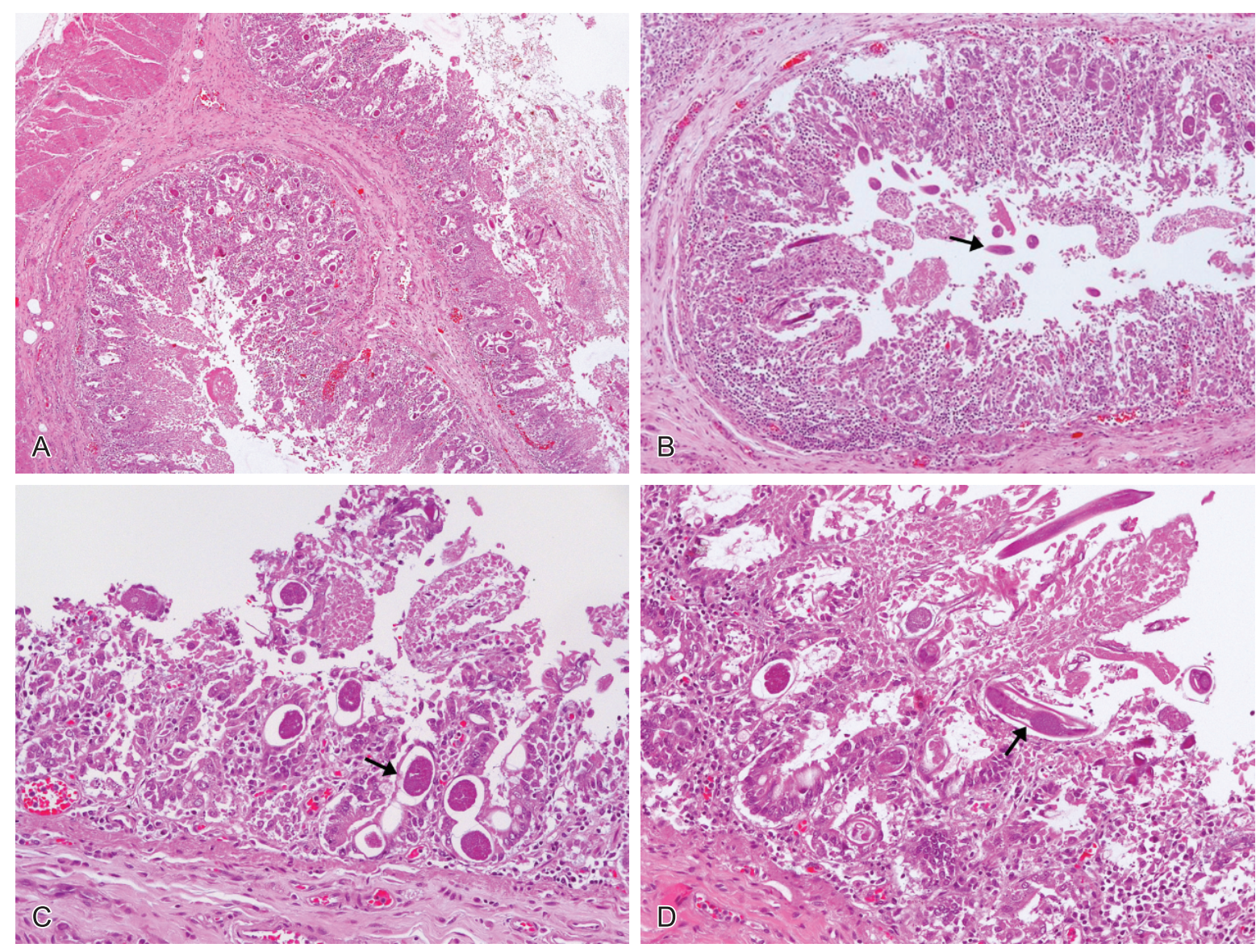

Figure 5 - A - Gross examination of a small intestine segment showing severe hemorrhagic enteritis and mucosal necrosis; B - Photomicrography (HE) of the small bowel showing females of $S$. stercoralis within the mucosa and into the lumen of the small intestine (arrows); C - Photomicrography (HE) of the small bowel showing female worms in cross section (arrow) and in $\mathbf{D}$ in longitudinal section.
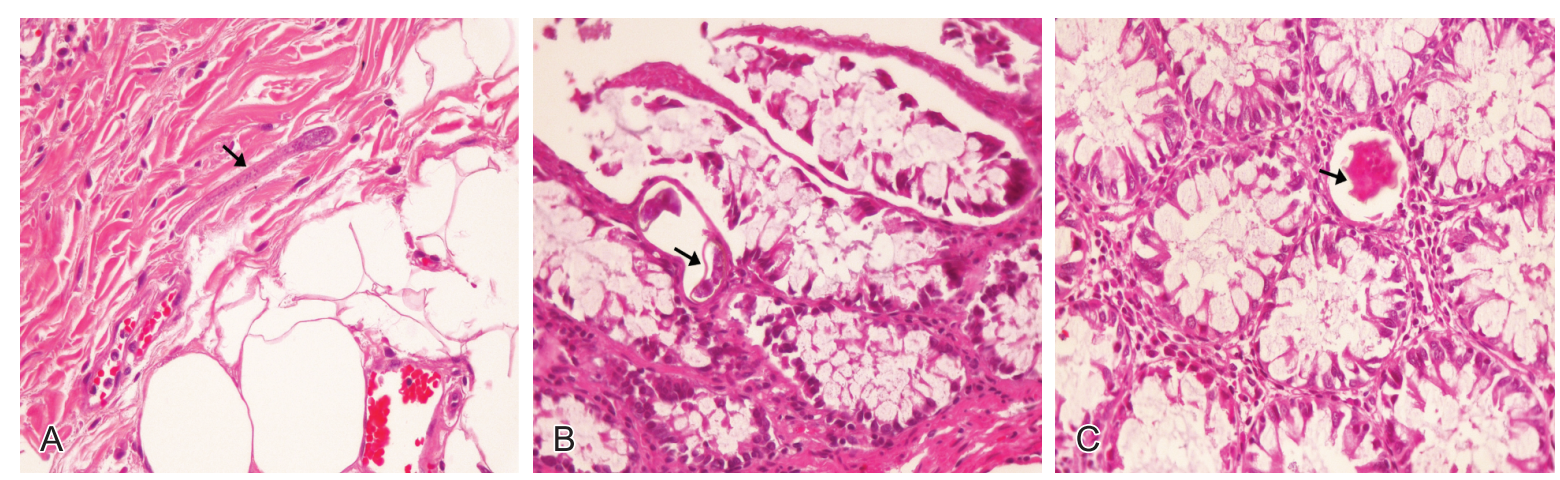

Figure 6 - Photomicrography (HE) of the large intestine showing: A - larvae of Strongyloides stercoralis within the submucosal layer without inflammatory response. B and C - Egg of Schistosoma mansoni within the mucosa (arrows).

Similarly, most cases of $S$. stercoralis infection happen without symptoms, especially in areas of high endemicity. This form tends to course chronically and diagnosis is usually accompanied by peripheral eosinophilia. When symptomatic, the clinical picture is highly variable depending on the interactions between host and parasite. ${ }^{1}$ In this case, the clinical forms include acute infection, chronic infection with intestinal diarrhea, hyperinfection, and disseminated syndrome. ${ }^{1}$
Disseminated disease refers to the presence of larvae outside the sites of the parasitic cycle. In the disseminated form, by definition, larvae are observed in almost all organs, where liver, brain, and heart are the most common areas involved. In the case reported here, larvae were found in the liver and supposedly in the brain, characterizing the disseminated infection. Moreover, the mild meningitis, observed at microscopy, could also represent an extension of the central nervous 

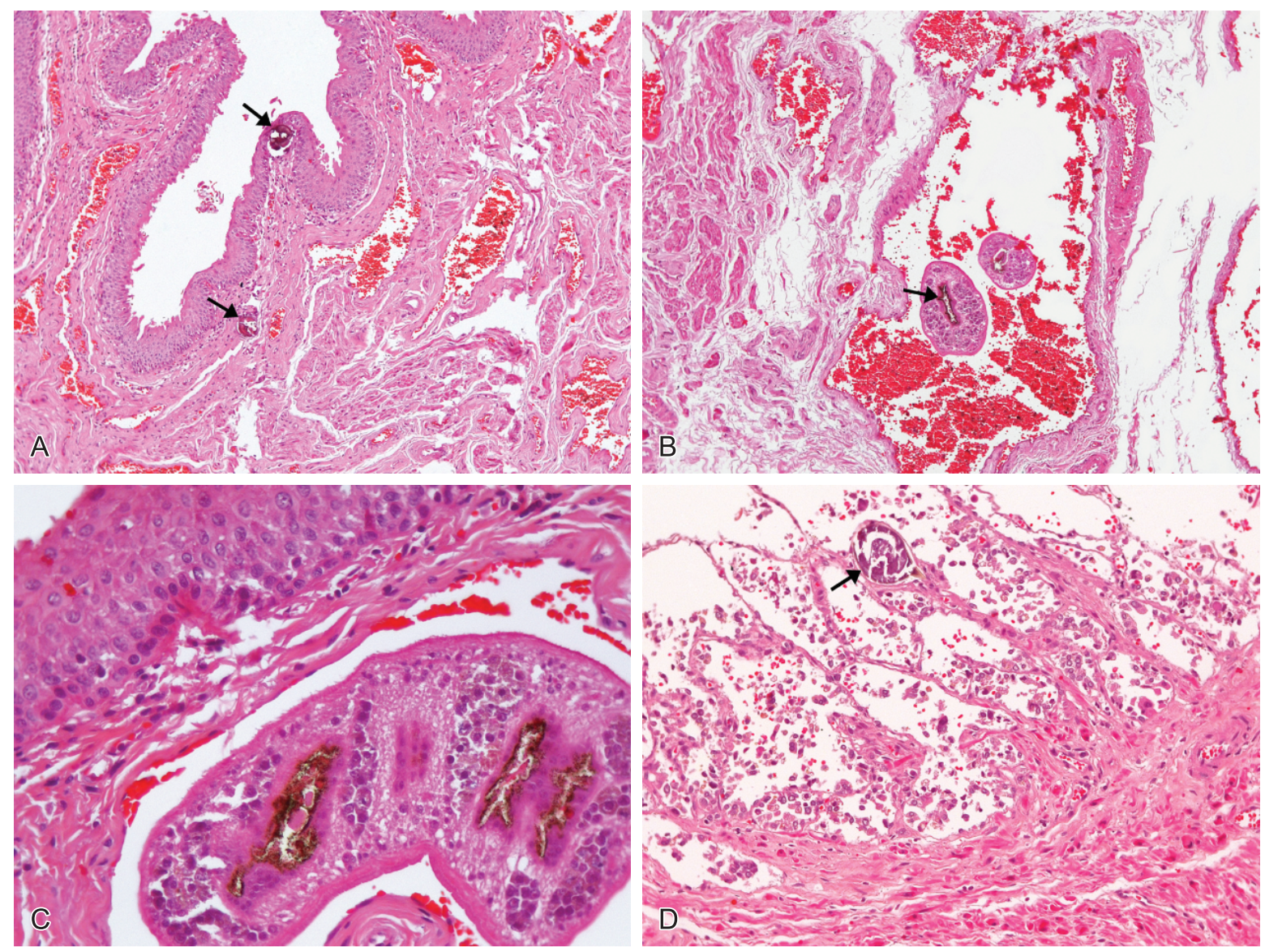

Figure 7 - Photomicrography (HE) of the urinary bladder showing: A - calcified eggs of S.mansoni within the mucosal layer (arrows); B and C - Adult worms of S. mansoni within a vessel in the wall of the bladder (arrows); D - Photomicrography (HE) of the seminal vesicle with the presence of eggs of S. mansoni (arrow).

system involvement by $S$. stercoralis, once other possible etiologies for chronic meningitis were ruled out. In their migration through the intestinal mucosa, the larvae may carry Gram-negative bacilli with them, resulting in bacteremia, metastatic infectious foci, and septic shock. The mortality rate in this form of the disease reaches $85 \%$ and is almost always associated with bacterial infections. ${ }^{1}$ This bacterial passage through the intestinal mucosa is also described in the $S$. stercoralis hyperinfection. ${ }^{9}$ Luna et al. recently described fever, pulmonary infiltrates, abdominal pain, and diarrhea as the most common signs and symptoms of severe forms of $S$. stercoralis infection. Periumbilical purple-colored lesions, although highly specific predictors of mortality, are usually a rare manifestation. ${ }^{10}$

Hyperinfection syndrome and the disseminated form of the disease have been recognized as being severe and potentially fatal conditions in immunocompromised individuals, especially those users of oral corticosteroids. However, the association between AIDS patients and the two most severe forms of strongyloidiasis is scarcely described, even in endemic areas. ${ }^{1,11-14}$ As far as we know, the association of strongyloidiasis, schistosomiasis, and AIDS has not been widely reported.

With the AIDS pandemia and its inherent deleterious effect on the immune system, an increased number of severe forms of $S$. stercoralis infection were expected, especially in countries like Brazil, but is not frequently observed in clinical practice. ${ }^{15}$

Until 2004, when a literature review was published, 35 patients were reported as being coinfected by HIV-1 and hyperinfection or disseminated infection. ${ }^{15}$ Ferreira et al. published the largest series in Brazil, ${ }^{13}$ comprising 25 cases of AIDS and strongyloidiasis co-infection. Among these 25 patients, 7 were diagnosed with hyperinfection syndrome, and all had a fatal outcome. In 2006, a case report of a patient with AIDS and S. stercoralis hyperinfection was also published in Brazil. ${ }^{14}$ In Latin America, a study regarding this coinfection, published in 2011, reported 21 cases in a 5 -year period. Out of this 21 cases, 5 expressed hyperinfection with a fatality rate of $40 \% .^{1}$ In this 
study, the authors observed a correlation between the CD4 count and lethality.

Schistosome infection and HIVIAIDS has been recently investigated. Downs et al. ${ }^{16}$, observed that Tanzanian women infected with Schistosoma hematobium are four-fold more likely to be HIV-1 seropositive than the women without schistosomiasis. These findings are consistent with the observations of Kjetland et al. ${ }^{17}$ Similarly, in Uganda, individuals who had antibodies to $S$. mansoni were significantly more likely to be HIV-1 seropositive than were persons without evidence of schistosome infection. ${ }^{18}$

Some hypotheses were carried out to explain this higher susceptibility. As approximately $90 \%$ of HIV infection occurs via the mucosa route, any condition that disrupts the integrity of a mucosal barrier or recruits a great number of HIV-1-suceptible cells to a site of virus exposure will increase host susceptibility to infection. Beyond human evidence, the increased susceptibility to viral infection, at mucosal sites, comes from studies of $S$. mansoniinfected rhesus macaques. In S. mansoni infection, eggs pass through the intestinal mucosa eliciting granulomatous inflammation in rectal tissues. Viral titration studies indicated that a 17-fold less virus was needed to infect animals with acute $S$. mansoni infection than the control animals. ${ }^{19}$ These observations suggest the predominant influence of schistosome infection on host susceptibility is a consequence of inflamed mucosae that permit the establishment of infection at a lower viral concentration..$^{20}$

Along with the increased susceptibility to HIV infection, schistosome coinfection may promote progression to disease by increasing the viral load. ${ }^{20}$ Higher viral loads in schistosome-infected hosts have been associated with increased viral replication within cells, as well as increased infection and depletion of cells associated with the immune response to schistosome infection..$^{19,21,22}$ Individuals coinfected with schistosome and HIV, that received early treatment, had a significantly slower rate of viral load increase than those whose treatment was delayed for 3 months. ${ }^{23}$ Studies in macaques infected by schistosome show a higher peak viral load despite being exposed to lower concentrations of virus than the control group. ${ }^{19}$

In addition to increasing viral replication, whether directly within antigen-specific cells ${ }^{19,22}$ or indirectly through activating other mechanisms associated with greater viral replication, ${ }^{22}$ schistosome infections may contribute to HIV-1 progression by reducing the ability of the host immune response to the control virus. ${ }^{20}$

On admission, the patient of this case report presented with an advanced immunosuppression valued by the CD4 count and viral load. According to the published studies, the coinfection of S. mansoni surely played an important role determining this exacerbated immunosuppression, facilitating the development of the disseminated strongyloidiasis.

The increased number of severe forms of strongyloidiasis in immunosuppressed patients may be explained by the decrease in the activation of humoral and cellular immune response (lymphocytes $\mathrm{T}$ helper). ${ }^{2}$ This lack of immune system activation may favor the transformation of rhabditiform into filariform larvae, which penetrate the intestinal mucosa or perianal skin. ${ }^{1}$ These changes are mostly observed in patients whose immune systems are suppressed by corticosteroids. ${ }^{1}$

Due to the possible parallelism that could be done between immunosuppression of diverse etiology and HIV infection, facilitation in the development of severe forms of $S$ stercoralis infection in AIDS patients would be expected. We dare raise the suspicion that, like in the case reported here, the coinfection with $S$. mansoni could enhance this phenomenon.

However, a cohort study ${ }^{15}$ found a negative relationship between the CD4+ cell count and the development of severe infections caused by $S$ stercoralis. In this study, ${ }^{15}$ there were significant negative rank correlations between CD4+ cell counts and the proportions of free-living male and female worms. Thus, in individuals with preserved immune function, direct development of $S$. stercoralis is favored; whereas, in individuals with lesser immune function, indirect development is relatively more common. ${ }^{15}$

Other factors, such as the persistent presence of $\mathrm{IgG}$ against the parasite, may represent a protective role in the response to the migration of the larvae in patients with coinfection of HIV and S. stercoralis.

Administration of high doses of steroids for the treatment of pulmonary infection due to Pneumocystis jiroveci or in the chemotherapy for 
non-Hodgkin lymphomas in patients with AIDS may be the facilitating mechanism for severe forms of infection with $S$ stercoralis development. We raise the suspicion that the coinfection by $S$. mansoni could also be on the list of facilitating comorbidities. Steroids, besides decreasing IgG production, also appear to have a direct trophic effect on the parasite, accelerating the transformation of rhabditiform larvae in filariform. ${ }^{1,15}$

Diagnosis of severe strongyloidiasis in AIDS patients may be challenging because of the conflict with other opportunistic infections and the presence of other diseases. The presence of unexplained gastrointestinal and pulmonary findings in these patients should be considered as alert signs. ${ }^{10}$

Non-specific laboratory tests seam to be of little help in the diagnosis of disseminated forms. The presence of eosinophils in peripheral blood is uncommon. Serological methods such as ELISA, Western Blot, and GPIA have low sensitivity. ${ }^{10}$

Definitive diagnosis is based on detection of larvae in feces, bronchial alveolar lavage, gastric aspirate, or biopsy of stomach, jejunum, lung or skin. ${ }^{10}$ In this case report, stool examination would have not only enabled the diagnosis of both parasites, but also enhanced the patient's immunity. The tracheal aspirate showed the higher positivity rate, followed by direct research in gastric aspirates, and biopsies of skin and lungs. ${ }^{10}$

Contrary to what has been reported in the literature, so far, the patient of this case report died by a $S$. stercoralis hyperinfection counting on the HIV virus infection as the only cause of immunosuppression. We draw attention to the difficult diagnosis. The empirical treatment for these cases should always be advisable, since the therapy is inexpensive, well tolerated, and reasonably effective.

\section{REFERENCES}

1. Corti M, Villafañe MF, Trione N, Risso D, Abuín JC, Palmieri O. Infección por Strongyloides stercoralis: estúdio epidemiológico, clínico, diagnóstico y terapéutico en 30 pacientes. Rev Chilena Infectol. 2011;28:217-22. Spanish. PMid:21879146. http://dx.doi.org/10.4067/S071610182011000300003

2. Keiser PB, Nutman TB. Strongyloides stercoralis in the immunocompromised population. Clin Microbiol
Rev. 2004;17:208-17. PMCid:321465. http://dx.doi. org/10.1128/CMR.17.1.208-217.2004

3. Freedman DO. Experimental Infection of human subject with Strongyloides especies. Rev Infect Dis. 1991;13:1221-6. http://dx.doi.org/10.1093/clinids/13.6.1221

4. Cimerman S, Cimerman B, Lewi DS. Prevalence of intestinal parasitic infections in patients with acquired immunodeficiency syndrome in Brazil. Int J Infect Dis. 1999;3:203-6. http:// dx.doi.org/10.1016/S1201-9712(99)90025-5

5. Beck L, Van-Lüme DSN, Souza JR, et al. Discriminating acute from chronic human schistosomiasis mansoni. Acta Trop. 2008;108:229-33. PMid:18851939. http://dx.doi. org/10.1016/j.actatropica.2008.08.012

6. Steinmann P, Keiser J, Bos R, Tanner M, Utzinger J. Schistosomiasis and water resources a review, metaanalysis and estimates of people at risk. Lancet Infect Dis. 2006;6:411-25. http://dx.doi.org/10.1016/S1473-3099 (06)70521-7

7. Lambertucci JR. Acute schistosomiasis mansoni: revisited and reconsidered. Mem Inst Oswaldo Cruz. 2010;105:422-35. http://dx.doi.org/10.1590/S0074-02762010000400012

8. Freitas LAR, Reis MG, Freitas JR, et al. Esquistossomose mansônica. In: Brasileiro Filho G, editor. Bogliolo patologia. 8. ed. Rio de Janeiro: Guanabara Koogan; 2011. p. 1387-98. Portuguese.

9. Husni RN, Gordon SM, Longworth DL, Adal KA. Disseminated strongyloides stercoralis infection in an immunocompetent patient. Clin Infect Dis. 1996;23:663. http://dx.doi.org/10.1093/ clinids/23.3.663

10. Luna OB, Grasseli R, Ananias M, et al. Estrongiloidíase disseminada: diagnóstico e tratamento. RBTI. 2007;19:463-8.

11. Kao D. Disseminated strongyloidiasis in a patient with acquired immunodeficiency syndrome. Arch Dermatol. 1996;132:977-8. http://dx.doi.org/10.1001/archderm.1996.03890320127027

12. Celedon JC, Mathur-Wagh U, Fox J, Garcia R, Wiest PM. Systemic strongyloidiasis in patients infected with the human immunodeficiency virus: a report of 3 cases and review of the literature. Medicine (Baltimore). 1994;73:256-63.

13. Ferreira MS, Nishioka S, Borges AS, et al. Strongyloidiasis and infection due to human immunodeficiency virus: 25 cases at a Brazilian teaching hospital, including seven cases of hyperinfection syndrome. Clin Infect Dis. 1999;28:154-5. PMid:10028097. http://dx.doi.org/10.1086/517188

14. Cimerman S, Teixeira MC, Girio D, et al. Hyperinfection strongyloides stercoralis in AIDS patient. Rev Panam Infectol. 2006;8:32-4.

15. Viney ME, Brown M, Omoding NE, et al. Why does HIV infection not lead to disseminated strongyloidiasis? J Infect Dis. 2004;190:2175-80. PMid:15551217. http://dx.doi. org/10.1086/425935 
16. Downs JA, Mguta C, Kaatano GM, et al. Urogenital schistosomiasis in women of reproductive age in Tanzania's Lake Victoria region. Am J Trop Med Hyg. 2011;84:364-9. PMid:21363971 PMCid:3042809. http://dx.doi.org/10.4269/ ajtmh.2011.10-0585

17. Kjetland EF, Ndhlovu PD, Gomo E, et al. Association between genital schistosomiasis and HIV in rural Zimbabwean women. AIDS. 2006;20:593-600. PMid:16470124. http://dx.doi. org/10.1097/01.aids.0000210614.45212.0a

18. Stabinski L, Reynolds SJ, Ocama P, et al. High prevalence of liver fibrosis associated with HIV infection: a study in rural Rakai, Uganda. Antivir Ther. 2011;16:40511. PMid:21555823 PMCid:3142695. http://dx.doi.org/10.3851//MP1783

19. Chenine AL, Shai-Kobiler E, Steele LN, et al. Acute schistosoma mansoni infection increases susceptibility to systemic SHIV clade C infection in rhesus macaques after mucosal virus exposure. PLoS Negl Trop Dis. 2008;2:e265. PMid:18648516 PMCid:2447882. http://dx.doi.org/10.1371/ journal.pntd.0000265

\section{Conflict of interest: None}

Submitted on: $25^{\text {th }}$ September 2012

Accept on: $3^{\text {rd }}$ November 2012

Correspondence: Divisão de Clínica Médica

Av. Prof. Lineu Prestes, 2565 - Cidade Universitária - São Paulo/SP - Brazil

CEP: 05508-000 - Phone: +55 (11) 3091-9200

E-mail: r.m.brandao@bol.com.br
20. Secor WE. The effects of schistosomiasis on HIVIAIDS infection, progression and transmission. Curr Opin HIV AIDS. 2012;7:254-9. PMid:22327410. http://dx.doi. org/10.1097/COH.0b013e328351b9e3

21. Secor WE, Shah A, Mwinzi PMN, et al. Increased density of human immunodeficiency virus type 1 coreceptors CCR5 and CXCR4 on the surfaces of CD4 ${ }^{+} T$ cells and monocytes of patients with Schistosoma mansoni infection. Infect Immun. 2003;71:6668-71. PMCid:219584. http://dx.doi. org/10.1128/IAI.71.11.6668-6671.2003

22. Mwinzi PNM, Karanja DMS, Colley DG, et al. Cellular immune responses of schistosomiasis patients are altered by human immunodeficiency virus type 1 coinfection. $J$ Infect Dis. 2001;184:488-96. PMid:11471107. http://dx.doi. org/10.1086/322783

23. Kallestrup P, Zinyama R, Gomo E, et al. Schistosomiasis and HIV-1 infection in rural Zimbabwe: effect of treatment of schistosomiasis on CD4 cell count and plasma HIV-1 RNA load. J Infect Dis. 2005;192:1956-61. PMid:16267767. http://dx.doi.org/10.1086/497696 